\title{
Paper
}

\section{A Study on Affects of Veilling Luminance on Pedestrian Visibility}

\author{
Shunsuke KOHKO*, Kohji KAWAKAMI* and Yoshiki NAKAMURA** \\ *IWASAKI ELECTRIC Co., Ltd. \\ **Tokyo Institute of Technology
}

Received February 16, 2007, Accepted April 25, 2008

\begin{abstract}
The author, et al. made quantitative analysis of the loss caused by glare in the luminance required for identification of faces by fixing eyes on the fact that the illuminance required for the identification of persons varies depending upon the value of threshold increment (TI) studied by Caminada and van Bommel. We could obtain the following results from the experiment we conducted for the above-mentioned quantitative analysis: (1) The luminance (illuminance) required for identification of faces is dependent upon the sum of "equivalent background luminance + equivalent veiling luminance due to glare light." (2) Reduction of the glare (equivalent veiling luminance) caused by luminaire can minimize the luminance (illuminance) required for face identification.
\end{abstract}

KEYWORDS: pedestrian, visibility, glare, equivalent veiling luminance

\section{Introduction}

This study is intended for achieving better outdoor luminous environment where glare and obtrusive lights can be controlled, with reduced consumption of energy.

Lighting is installed on roadways, streets, squares, plazas, etc. to ensure security of people during the nighttime. Key requirements for the lighting include sufficient luminance to provide identification of approaching persons and help assume a posture of escape, if necessary.

E. T. Hall ${ }^{11}$ shows that one needs the minimum distance of $4 \mathrm{~m}$ to detect approaching persons as dangerous or suspicious and take the defensive immediately. Based on this theory, Caminada and van Bomme1 ${ }^{2)}$ examined illuminance required for identification of persons at the viewing distance of $4 \mathrm{~m}$ on real streets. The result of this study suggested that a semicylindrical illuminance of $0.8 \mathrm{~lx}$ was required for the case of threshold increment (TI) of 8 to 15 . Using their proposed figure, the required illuminance is estimated at about $0.6 \mathrm{~lx}$ for the case where TI is less than 2 . This value suggests that identifications of persons are affected by glare and that therefore, semicylindrical illuminance must be increased by about $0.2 \mathrm{~lx}$ as compared with the condition without glare. Nevertheless, Caminada and van Bommel did not deepen the affect of glare on identification of persons.

Kawakami ${ }^{3}$, on the other hand, conducted experiments in a laboratory environment without glare, showing the relationship between background luminance and the luminance required for identification of persons. One of his conclusions, for example, shows that in order that observers can "be barely identifiable the facial expression of an individual" standing at a viewing distance of $5 \mathrm{~m}$, a luminance of approximately $0.23 \mathrm{~cd} / \mathrm{m}^{2}(2.4 \mathrm{~lx})$ is required under the condition of background luminance of $0.1 \mathrm{~cd} / \mathrm{m}^{2}$ or less. Likewise, Miyamae, et al. ${ }^{4)}$ made experiments on identification of persons using images, showing that a vertical illuminance of about $2 \mathrm{~lx}$ or more is required so that it is possible for observers to "identify who person is (an acquaintance or not)" at a viewing distance of $5 \mathrm{~m}$. These studies, however, did not take into consideration the effect of glare on identification of persons.

As above, therefore, this author, et al. conducted an experiment on indoor face visibility in order to obtain quantification of the degree of loss caused by glare in the luminance required for identification of persons, through measurements of glare expressed in values of equivalent veiling luminance. This report describes the overview of the experimental study we conducted.

\section{Method of experiment}

The method of experiment was that, using background luminance and equivalent veiling luminance as parameters, observers controlled illuminance of the face so that they could identify the face of test target.

\subsection{Experimental setting}

The author, et al. prepared an experimental setup as 
shown in Figure 1 and Figure 2, in a dark room in which inter-reflections can be ignored. Blackout curtains or matt papers equivalent to N4.5 (Munsell value) was used on the background, and 2 units of $40 \mathrm{~W}$ fluorescent lamps (5000K) were installed so that luminance distributions as uniform as possible can be obtained. In addition, luminance values were controlled by means of dimming of light sources and change of background surface. Gray matt cloths (equivalent to N3) were placed on the floor. Reflector lamps (5900K) were used as light sources for making glare (equivalent veiling luminance) and lighting the face. The light sources for glare were installed in the direction of the angle of elevation $8.5 \mathrm{deg}$. from the eye of observers. This was based on the assumption the luminaries were usually installed at a height of $4.5 \mathrm{~m}$ from the ground level and at a distance of $20 \mathrm{~m}$ ahead.

\subsection{Test target and presented conditions}

14 different conditions for test target (full-size dummy), as shown in Table 1, were presented using the above-mentioned parameters, i.e., background luminance and equivalent veiling luminance (glare). The reflectance of cheeks of the test target was $30 \%$.

\subsection{Method of assessment}

Evaluation items were set up according to the visibility of faces required for ensuring nighttime security, which were based on the identification of the positions of the elements of face, i.e., eyes, nose and mouth. This idea is based on the study of Okuda, et al.5), assuming that visibility of face is explained as per Table 2 .

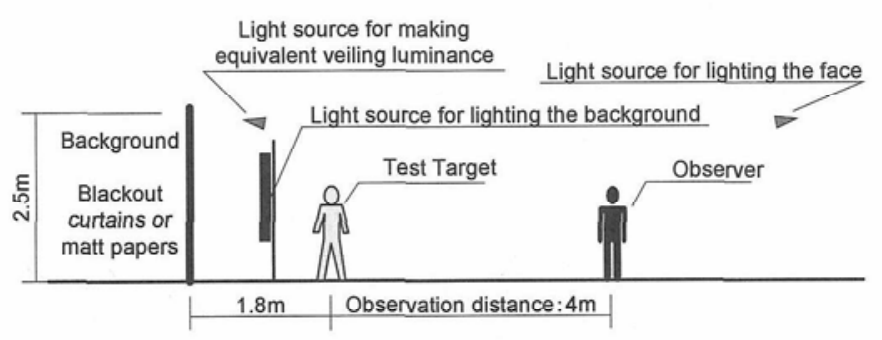

Figure 1 Experimental environment (1)

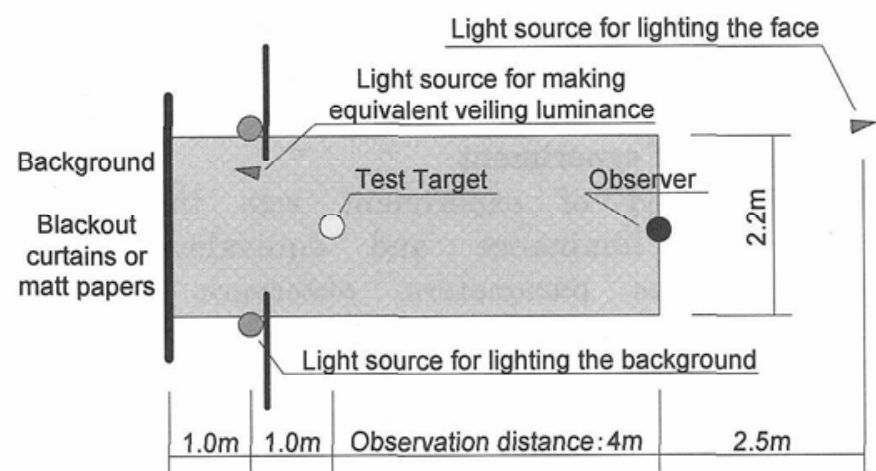

Figure 2 Experimental environment (2)
In our evaluation experiment, observers were first told that the evaluation items for visibility of faces were as listed in Table 2, and the following instruction was given to them:

$<$ Instruction $>$

Suppose that you are walking along a strange street. And adjust the light to the lighting level at which you can identify the positions of eyes, nose and mouth of the person (dummy) standing ahead. Adjust the light two ways in accordance with the instruction to be given: gradually increase light from the lightsout condition and gradually dim light from the sufficiently bright condition.

Table 1 Test Target

\begin{tabular}{c|c|c}
\hline No. & $\begin{array}{c}\text { Background } \\
\text { luminance }\end{array}$ & $\begin{array}{c}\text { Equivalent veiling } \\
\text { luminance }\end{array}$ \\
\hline 1 & 0.3 & 0.01 \\
\hline 2 & 0.3 & 0.03 \\
\hline 3 & 0.3 & 0.1 \\
\hline 4 & 0.3 & 0.3 \\
\hline 5 & 0.3 & 1.0 \\
\hline 6 & 1.0 & 0.075 \\
\hline 7 & 1.0 & 0.1 \\
\hline 8 & 1.0 & 0.3 \\
\hline 9 & 1.0 & 1.0 \\
\hline 10 & 1.0 & 3.0 \\
\hline 11 & 3.0 & 0.1 \\
\hline 12 & 3.0 & 0.3 \\
\hline 13 & 3.0 & 1.0 \\
\hline 14 & 3.0 & 3.0 \\
\hline
\end{tabular}

Table 2 Order of Evaluation Items for Visibility of Faces

\begin{tabular}{|c|c|c|}
\hline Rank & $\begin{array}{c}\text { Measure for visibility } \\
\text { of entire face }\end{array}$ & $\begin{array}{l}\text { Measure for visibility of } \\
\text { facial elements }\end{array}$ \\
\hline \multirow[t]{3}{*}{ Low } & & Line of sight \\
\hline & Expression & $\begin{array}{l}\text { Eyebrow shape } \\
\text { Eye shape Open/closed eye } \\
\text { Mouth shape } \\
\text { Open/closed mouth }\end{array}$ \\
\hline & $\begin{array}{c}\text { Individual } \\
\text { identification }\end{array}$ & $\begin{array}{l}\text { Eyebrow position } \\
\text { Eye position } \\
\text { Mouth position } \\
\text { Nose position } \\
\text { Ear position }\end{array}$ \\
\hline High & Sex & Hair style, Hair length \\
\hline
\end{tabular}


Table 3 Observers

\begin{tabular}{c|c|c|c|c|c}
\hline & Twenties & Thirties & Fourties & Fifthies & Total \\
\hline Male & 7 & 1 & 2 & 0 & 10 \\
\hline Female & 4 & 2 & 0 & 0 & 6 \\
\hline Total & 11 & 3 & 2 & 0 & 16 \\
\hline
\end{tabular}

Next, they were adapted to a given background luminance for 10 minutes and had exercises three times before starting the experiment. During the experiment, the luminance of the test target face (at a visual angle of 1 deg.) and the equivalent veiling luminance were measured from each observer's eye position at the time when he/she "identified the positions of eyes, nose and mouth of the dummy" under each of the presented conditions mentioned above. In addition, the equivalent veiling luminance was measured with a luminance meter that installed a glare lens. It included background and light source. The 14 different types of test targets (see Table 1) were exhibited at random to each observer at an observation distance of $4 \mathrm{~m}$.

\subsection{Observers}

A total of 16 observers as listed in Table 3 took part in the experiment.

\section{Results}

The resulting data were confirmed to be evaluated based on average values because there were no particular singular evaluation data among observers and the evaluation data are distributed normally (The standard deviation was from 0.06 to 0.37.). Next, using Welch's $t$ test as the measure, we checked and verified that there was no variance due to the difference in the order of lighting adjustment (between the cases where light is gradually increased from the lightsout condition and where light is gradually dimmed from the sufficiently bright condition). Based on these verifications, we made an analysis of the experimental data using the average of all the observers.

The average experimental values used here refer to the level of visibility at which observers identified the positions of eyes, nose and mouth of the dummy, which is hereafter called the "required face luminance."

We depicted the relationship between the required face luminance values and average values of the measured equivalent veiling luminance regarding the background luminance as parameter (Figure 3). This figure shows that equivalent veiling luminance changes 150 -fold while the required face luminance changes 10 -fold.
Then, the following can be concluded from the experimental results:

(1) The required face luminance increases as equivalent veiling luminance (glare) increases.

(2) The effects of both background luminance and equivalent veiling luminance must be conjointly taken into account in the analysis to estimate the possibility of face visibility in the actual environment.

\section{Discussion}

4.1 Relationship of required face luminance with background luminance and with equivalent veiling luminance

The background luminance in the experimental environment is controlled as a relatively uniform luminance distribution. The actual lighted environment during the night, however, is very complicated, and the level of uniformed background luminance that would be expected to correspond to the luminance distribution of a particular night is unknown. We think that background luminance, equivalent veiling luminance by background luminance and equivalent veiling luminance by glare influence the required face luminance.

However, measured equivalent veiling luminance is a superimposed value of equivalent veiling luminance by background luminance and equivalent veiling luminance by glare. This study aims for getting knowledge on how much the equivalent veiling luminance by glare influence on identification of a face. We tried to separate each influence of background luminance, equivalent veiling luminance by background luminance and equivalent veiling luminance by glare. Equivalent veiling luminance by glare can be easily calculated by subtracting the equivalent veiling luminance without glare from measured equivalent veiling luminance. The equivalent veiling luminance without glare used the equivalent veiling luminance of environment ${ }^{6}$ ) which we calculated from an image. Background luminance can be calculated by convolution of $\mathrm{N}$-filter into a luminance distribution image. This idea is results of research of Dr. Nakamura7).

The filter was designed to represent the contrast of luminance between visual targets and background which has intricate luminance distributions. This contrast of luminance can be calculated by convolution of $\mathrm{N}$-filter into a luminance distribution image. In other words, it refers to a method that expresses a complicated background luminance distribution surrounding a visual target as a single value of background luminance (hereafter called the "equivalent background luminance"). 


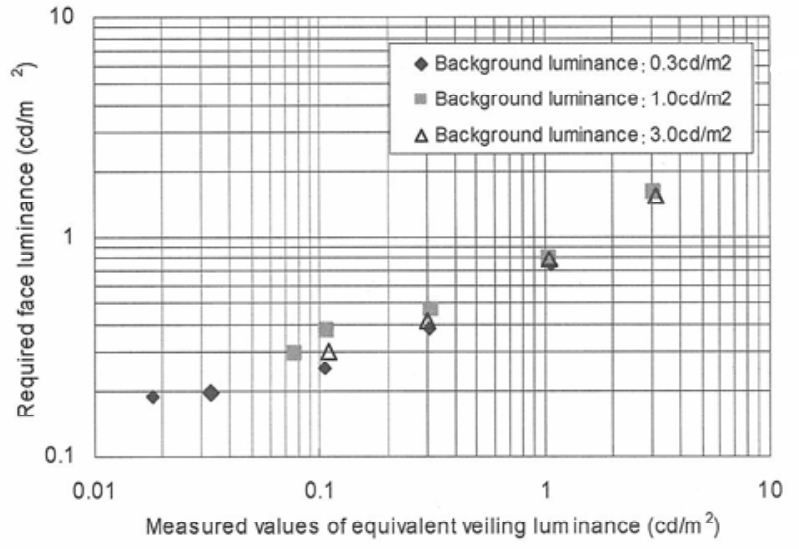

Figure 3 Relationship between equivalent veiling luminance and required face luminance

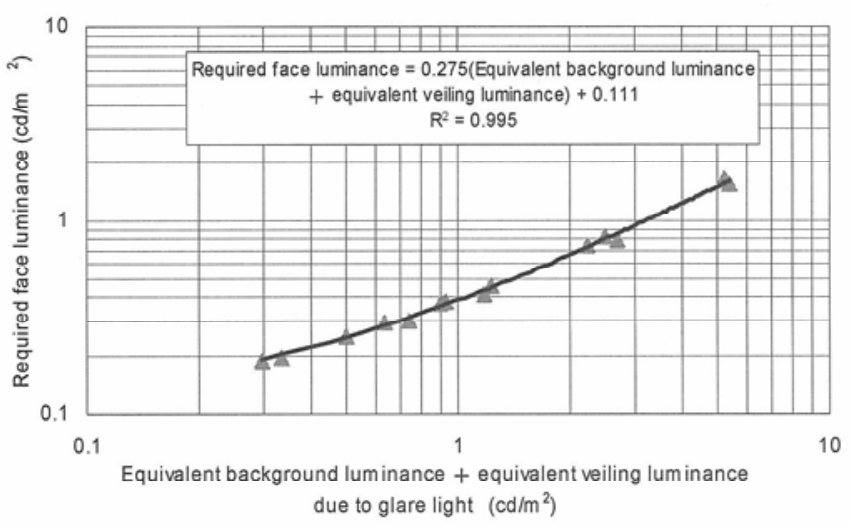

Figure 4 Relationship between required face luminance and the sum of equivalent background luminance + equivalent veiling luminance

We considered the area of the face to be one unit, and calculated the average luminance of this area (Lface) and the contrast of face and surrounding (C), and led equivalent background luminance (Leb) as follows.

$$
\text { Leb }=\text { Lface } / \mathrm{C}
$$

All images consisted of $1280 \times 960$ pixels, and 53.4 degrees in field angle. And they had range from 0.05 to $2000 \mathrm{~cd} / \mathrm{m}^{2}$.

In addition, the luminance by glare was excluded from calculation of Leb. Because it had exceeded the measurement upper limit. Therefore, luminance of glare source is not included in equivalent background luminance.

The results of our experiment are shown in Figure 4, in which the values of "equivalent background luminance + equivalent veiling luminance due to glare light" are laid out along the axis of abscissas, and the required face luminance values, along the axis of ordinates. As can be seen in the figure, it was revealed that there is a significant correlation $\left(R^{2}=0.995\right)$ between the required face luminance and the "equivalent background luminance + equivalent veiling luminance due to glare light," as defined by Expression (1) below:

$$
\begin{aligned}
& L_{f}=0.275 \cdot\left(L_{b}{ }^{\prime}+L_{e q}\right)+0.111 \\
& \text { where } \\
& L_{f}: \text { Required face luminance }\left(\mathrm{cd} / \mathrm{m}^{2}\right) \\
& L_{b}{ }^{\prime} \text { : Equivalent background luminance }\left(\mathrm{cd} / \mathrm{m}^{2}\right) \\
& L_{e q}: \text { Equivalent veiling luminance }\left(\mathrm{cd} / \mathrm{m}^{2}\right)
\end{aligned}
$$

This figure indicates better correlation than that in the previous chart.

Hence, the author, et al., hold that the required face luminance can be estimated by superposing equivalent veiling luminance over the equivalent background luminance calculated using $\mathrm{N}$-filter under our experimental conditions.

\subsection{Relationship between visibility of faces and spatial distributions of luminous intensity in luminaires}

The luminance required for identification of faces is affected by the glare (equivalent veiling luminance) caused by luminaires. We compare the identifications of faces using two types of luminaries in order to consider better spatial distributions of luminous intensity from luminaries (see Figure 5 and Figure6).

Luminaire A (Figure 5) is an example with reduced glare, and Luminaire B (Figure 6) is an example with uncontrolled glare. Suppose that these luminaires are installed under the conditions shown in Table 4. The results of road surface illuminance as well as semicylindrical illuminance at the height of pedestrian's eye $(1.5 \mathrm{~m})$, obtained under the aforementioned conditions are graphically depicted in Figures 7, 8, 9 and 10. Shown in Figure 11, on the other hand, are the data of equivalent veiling luminance calculated at the height of pedestrian's eye in the longitudinal center of road. Averages of the respective illuminance and luminance values are summarized in Table 5.

Next, we will analyze difference in visibility as may be caused by the difference of spatial distribution of luminous intensity. This analysis is made supposing the positional relation as shown in Figure 12: the observer stands face to face with the visual target (face) at a distance of $4 \mathrm{~m}$ in the longitudinal center zone (20-m long) of long road, along which luminaires are continuously equipped. An equivalent background luminance of $1 \mathrm{~cd} / \mathrm{m}^{2}$ is supposed for this situation. 


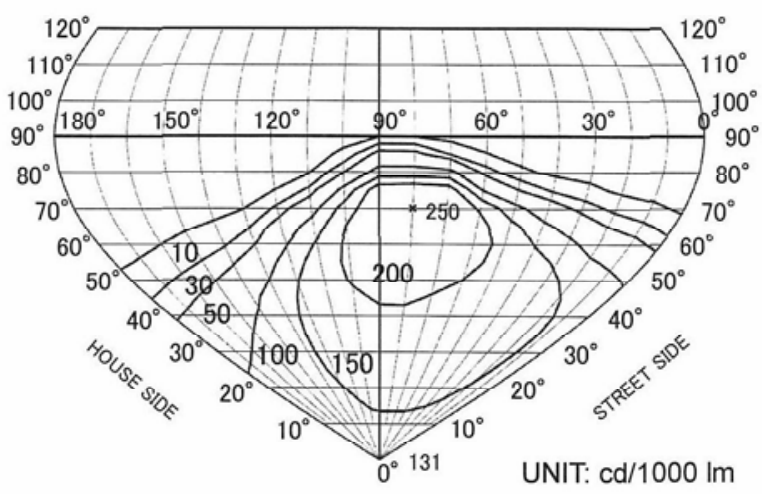

Figure 5 Spatial distribution of luminous intensity for luminaire $A$

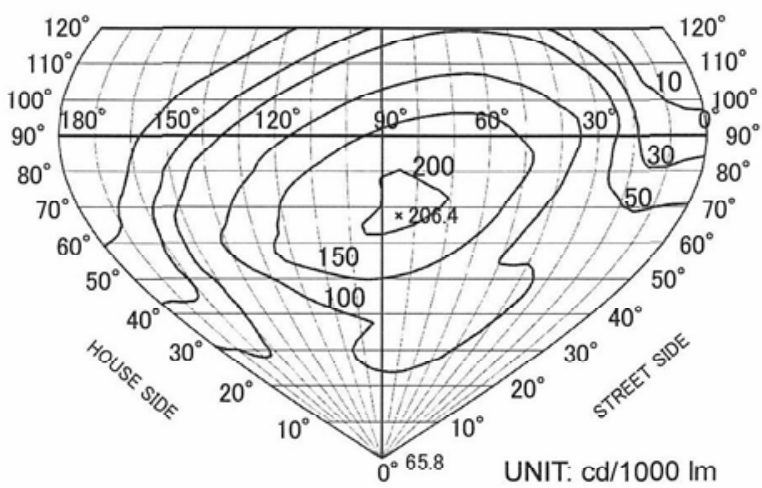

Figure 6 Spatial distribution of luminous intensity for luminaire $B$

Table 4 Installation Conditions

\begin{tabular}{l|c|c}
\hline & $\begin{array}{c}\text { Luminaire A } \\
\text { (Fig. 5) }\end{array}$ & $\begin{array}{l}\text { Luminaire B } \\
\text { (Fig. 6) }\end{array}$ \\
\hline Width of road (m) & \multicolumn{2}{|c}{4.0} \\
\hline Spacing in the installation (m) & 20 (Continuous lighting) \\
\hline Mounting height (m) & 5.0 \\
\hline Lamp (Luminous flux) & $\begin{array}{c}\text { Compact fluorescent lamp, } \\
32 \mathrm{~W}(2900 \text { Im) }\end{array}$ \\
\hline
\end{tabular}

Table 5 Averages Values of Illuminance and Luminance

\begin{tabular}{l|c|c}
\hline & $\begin{array}{c}\text { Luminaire A } \\
\text { (Fig. 5) }\end{array}$ & $\begin{array}{c}\text { Luminaire B } \\
\text { (Fig. 6) }\end{array}$ \\
\hline $\begin{array}{l}\text { Road surface illuminance } \\
\text { (Average value for 20-m long } \\
\text { section of 4-m wide road) }\end{array}$ & $6.2 \mathrm{~lx}$ & $4.0 \mathrm{~lx}$ \\
\hline $\begin{array}{l}\text { Semicylindrical illuminance } \\
\text { (Average value for 20-m long } \\
\text { section of 4-m wide road; at } \\
\text { a height of 1.5 m) }\end{array}$ & $3.1 \mathrm{~lx}$ & $2.7 \mathrm{~lx}$ \\
\hline $\begin{array}{l}\text { Equivalent veiling luminance } \\
\text { (Average value for 20-m long } \\
\text { longitudinal center zone of } \\
\text { road). }\end{array}$ & $0.175 \mathrm{~cd} / \mathrm{m}^{2}$ & $0.486 \mathrm{~cd} / \mathrm{m}^{2}$ \\
\hline
\end{tabular}

Note: The above illuminance values are calculated based on the maintenance factor of 0.7 .

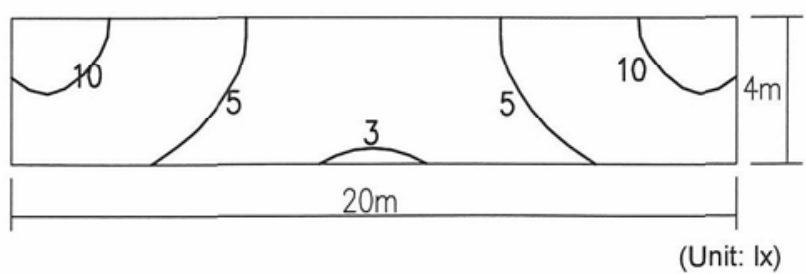

Note: Values indicated on curves denote maintenance illuminance.

Figure 7 Horizontal illuminance distribution (Luminaire A)

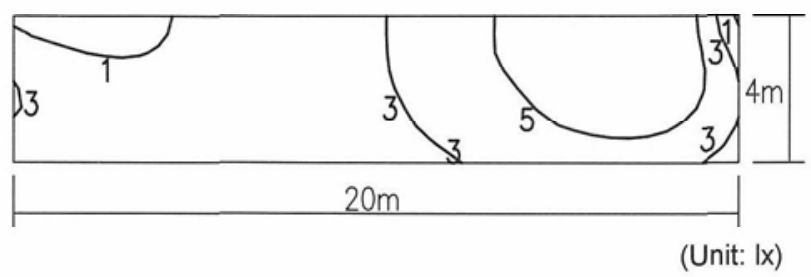

Note:Values indicated on curves denote maintenance illuminance. When the photo detector faces the right.

Figure 8 Semicylindrical illuminance distribution (Luminaire A)

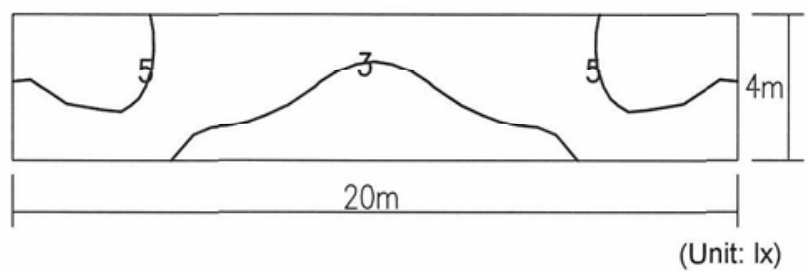

Note: Values indicated on curves denote maintenance illuminance.

Figure 9 Horizontal illuminance distribution (Luminaire B)

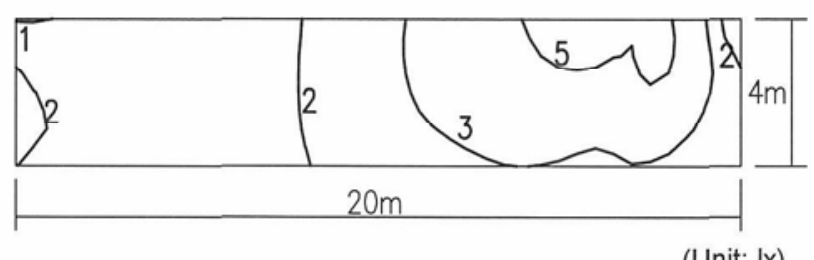

Note: Values indicated on curves denote maintenance illuminance. When the photo detector faces the right.

Figure 10 Semicylindrical illuminance distribution (Luminaire B)

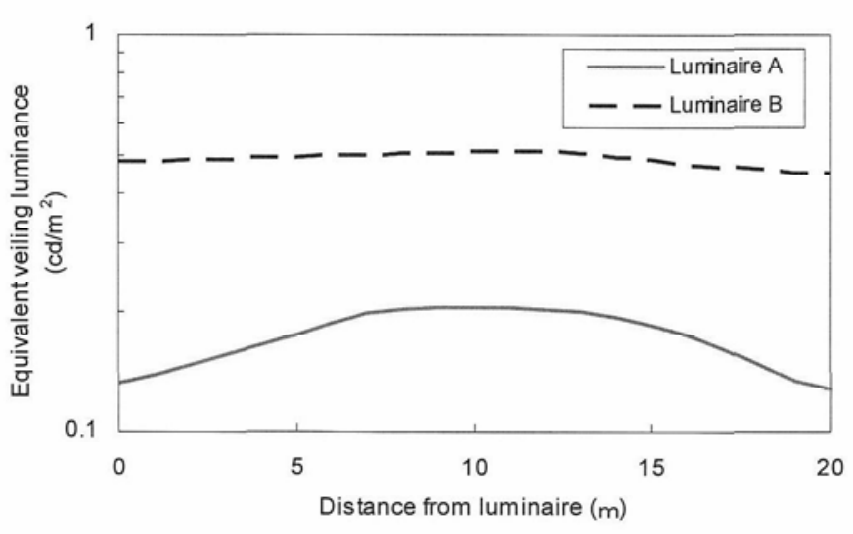

Figure 11 Equivalent veiling luminance due to glare 


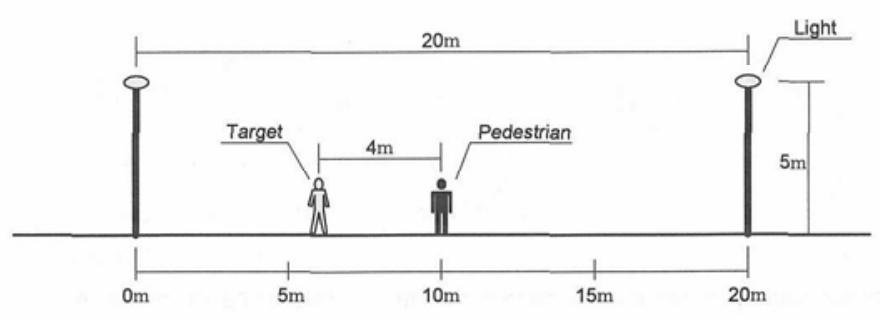

Figure 12 Positional relation between pedestrian and target

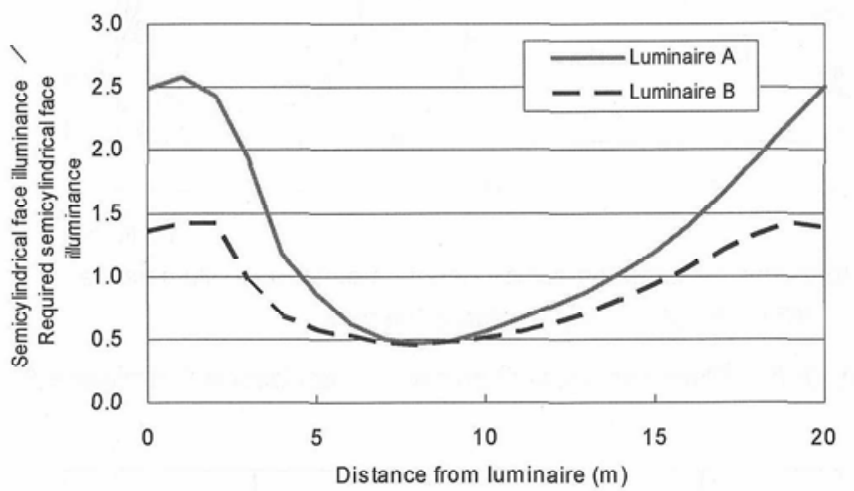

Figure 13 Evaluation of visibility of faces in the cross-sectional center zone of road

The luminance required for identification of persons is estimated using Expression (1) based on the sum of the equivalent veiling luminance (Figure 11) and the equivalent background luminance $\left(1 \mathrm{~cd} / \mathrm{m}^{2}\right)$. The value obtained from Expression (1) is then converted ${ }^{8)}$ into a value of semicylindrical illuminance using Expression (2) below.The resulting illuminance value is hereafter called the "semicylindrical illuminance required for identification of persons."

$$
E_{s c} \fallingdotseq \pi \cdot L_{f} / \rho
$$

$$
\begin{aligned}
& \text { where } \\
& E_{s c}: \text { Semicylindrical illuminance }(\mathrm{lx}) \\
& L_{f}: \text { Face luminance }\left(\mathrm{cd} / \mathrm{m}^{2}\right) \\
& \rho \quad: \text { Reflectance of face }
\end{aligned}
$$

Figure 13 graphically depicts the semicylindrical illuminance required for identification of faces in relation with the same that can be obtained from Luminaire A or Luminaire B. It indicates that an individual face can be identified if the ratio is 1.0 or higher.

The figure shows that Luminaire A allow identification of individual faces within a section of $12 \mathrm{~m}(60 \%)$ of the total $20 \mathrm{~m}$ long zone of road, and Luminaire B, within a section of $8 \mathrm{~m}(40 \%)$ of the same total zone of road. Luminaire A showed a slightly higher value than that for Luminaire B with respect to the mean of semicylindrical illuminance for the $20-\mathrm{m}$ long zone of road. Nonetheless, Luminaire A provided $20 \%$ longer area in terms of the possibility of face identification as compared with Luminaire B. This suggests that there is a difference in glare (equivalent veiling luminance) between the two luminaires. Although Luminaire $\mathrm{B}$ is designed to provide strong luminous intensities in the high vertical angle (horizontally) so that high semicylindrical illuminance reaches far away, those horizontal lights end with adverse effects in that it increases glare (equivalent veiling luminance), adversely affecting the visibility of faces.

Hence, it is recommended that good luminaires have spatial distribution of luminous intensity with sufficiently controllable horizontal lights.

\subsection{Examination of energy loss caused by glare}

In this section we intend to convert the decrease of visibility of faces due to glare into electric energy loss, using the average values of semicylindrical illuminance and equivalent veiling luminance for the $20-\mathrm{m}$ long zone of road. For this purpose, it is supposed that Luminaires $\mathrm{A}$ and $\mathrm{B}$ are installed under the conditions identical to those used in 4.2 (see Table 4).

First, difference in the required semicylindrical illuminance between the two luminaires due to the variance of glare (equivalent veiling luminance) is calculated.

Using the average equivalent veiling luminance for the $20-\mathrm{m}$ long zone of road and the supposed equivalent background luminance $\left(1 \mathrm{~cd} / \mathrm{m}^{2}\right)$, the average semicylindrical illuminance value is obtained from Expression (2). The resulting difference between the two luminaires is $0.89 \mathrm{~lx}$ (semicylindrical illuminance), as shown in Table 6.

In order to obtain the same level of visibility of faces on Luminaire A and Luminaire B, design of the latter must allow its semicylindrical illuminance to be increased at least $0.89 \mathrm{~lx}$ (Because equivalent veiling luminance increases by raising semicylindrical illuminance to $0.891 \mathrm{lux}$, a further illuminance increase to the increment of equivalent veiling luminance is also needed.) or more, that is, Luminaire B should have average semicylindrical illuminance of $3.59 \mathrm{~lx}$ (= $2.7 \mathrm{~lx}+0.89 \mathrm{~lx}$ ) for the $20-\mathrm{m}$ long zone of road. Hence, the lamp of Luminaire B requires luminous flux of $3,850 \mathrm{~lm}$ (an increase of about $950 \mathrm{~lm}$ from the rated luminous flux), which is equivalent to approximately $10 \mathrm{~W}$ when converted into wattage of a compact fluorescent lamp.

As above, therefore, it can be said that Luminaire B is wasting electric energy of about at least $10 \mathrm{~W}$ due to glare as compared with Luminaire A. 
Table 6 Energy Loss Caused by Glare

\begin{tabular}{|c|c|c|}
\hline & Luminaire A (Fig. 5) & Luminaire B (Fig. 6) \\
\hline Luminous flux of a $32-W$ compact fluorescent lamp (Im) & \multicolumn{2}{|c|}{2900} \\
\hline $\begin{array}{l}\text { Semicylindrical illuminance (Ix) } \\
\text { (at a height of } 1.5 \mathrm{~m} \text {; average value) }\end{array}$ & 3.1 & 2.7 \\
\hline $\begin{array}{l}\text { Equivalent veiling luminance }\left(\mathrm{cd} / \mathrm{m}^{2}\right) \\
\text { (at a height of } 1.5 \mathrm{~m} \text { in the center zone of road; average } \\
\text { value for a length of } 20 \mathrm{~m} \text { ) }\end{array}$ & 0.175 & 0.486 \\
\hline $\begin{array}{l}\text { Semicylindrical illuminance required for identification of } \\
\text { faces when the above equivalent veiling luminance is } \\
\text { present } \\
\text { (Given an equivalent background luminance of } 1 \mathrm{~cd} / \mathrm{m}^{2} \text { ) }\end{array}$ & 4.55 & 5.44 \\
\hline Difference between the above values $(\mathrm{Ix})$ & \multicolumn{2}{|c|}{0.89} \\
\hline Illuminance to obtain equivalent visibility of faces (Ix) & 3.1 & $2.7+0.89$ \\
\hline Required luminous flux of lamp $(\mathrm{lm})$ & 2900 & 3850 \\
\hline Required lamp wattage $(W)$ & 32 & 42 \\
\hline
\end{tabular}

\section{Conclusion}

The author, et al. made quantitative analysis of the loss caused by glare in the luminance required for identification of faces by fixing eyes on the fact that the illuminance required for the identification of persons varies depending upon the value of threshold increment $(T I)$ studied by Caminada and van Bommel.

We could obtain the following results from the experiment we conducted for the above-mentioned quantitative analysis:

(1) The luminance (illuminance) required for identification of faces is dependent upon the sum of "equivalent background luminance + equivalent veiling luminance due to glare light".

(2) Reduction of the glare (equivalent veiling luminance) caused by luminaire can minimize the luminance (illuminance) required for face identification.

The result of our study indicates that the reduction of equivalent veiling luminance of $0.1 \mathrm{~cd} / \mathrm{m}^{2}$ can cut the required luminance by $0.028 \mathrm{~cd} / \mathrm{m}^{2}(0.28 \mathrm{~lx})$ given an equivalent background luminance at a level of $1 \mathrm{~cd} / \mathrm{m}^{2}$.

(3) We also examined the decrease of face visibility due to glare in terms of electric energy loss. In case of the use of a $32-\mathrm{W}$ compact fluorescent lamp, Luminaire $\mathrm{B}$, designed with uncontrolled glare, is wasting electric energy of about $10 \mathrm{~W}$ due to its glare as compared with Luminaire A.

\section{References}

(1) E.T. Hall: The hidden dimension, Anchor Books, New York (1966).

(2) J. F. Caminada and W. J. M. van Vommel: New lighting considerations for residential area, International Lighting Review, pp.69-75 (1980).

(3) K. Kawakami: The Relation between the Identification of Expression of Human Face and Semi-cylindrical Illuminance, J. Illum. Engng. Inst. Jpn., Vol.70, pp.282-287 (1986).

(4) A. Miyamae and T. Takeuchi: Illuminance to be provided for residential roads, J. Illum. Engng. Inst. Jpn., Vol.73, pp.303-306 (1988).

(5) S. Okuda and R. Satoh: Study on Establishing an Evaluation Method for the Visibility of the Human Face, J. Illum. Engng. Inst. Jpn., Vol.84, pp.809-814 (2000).

(6) K. Kawakami, S. Kohko and T. Uozumi: Applicability of CIE's Glare (GR) Evaluation System for Outdoor Facilities to Indoor Sports Facilities, J. Light \& Vis. Env., Vol.23, No.2, pp.31-37(1999).

(7) Y. Nakamura: A Technique for Quantatively Examining Luminance Contrast in Lighting Environment, J. Illum. Engng. Inst. Jpn., Vol.84, pp.522-528 (2000).

(8) K. Kawakami: The relationship between the luminance of the human face and the semicylindrical illuminance, J. Illum. Engng. Inst. Jpn., Vol.74, pp.348-353 (1990). 